\title{
PID-Controlled Laparoscopic Appendectomy Device
}

\author{
Abdul Rahman Dabbour, Asif Sabanovic, Meltem Elitaş \\ Faculty of Engineering and Natural Sciences, Sabancı University, Istanbul, Turkey \\ \{dabbour, asif,melitas\}@sabanciuniv.edu
}

\begin{abstract}
Minimally invasive surgery is a surgical method, which boasts many advantages over regular surgeries, such as decreasing the risks involved by minimizing the incision area, thus reducing the risk of infection compared to invasive surgeries. Laparoscopic surgery tools built for this purpose are mostly singular in function, which means that it requires multiple incisions for multiple tools or changing tools using the same incision during the operation. This project attempts to motorize an affordable multifunctional mechanical surgical tool prototype. The tool is designed using SolidWorks and controlled using MATLAB/Simulink. Three motors are used to motorize the multifunctional laparoscopic tool and their control architectures made it more precise and more accurate for noninvasive operations. It is shown that with some physical modifications and simple PID control, the multifunctional laparoscopy tool can be controlled and modified for the robotic-assisted surgery. Possible future improvements include attachment of the cameras and wireless control for the tele-operational applications.
\end{abstract}

\section{Introduction}

Laparoscopic surgery, widely known as minimally invasive surgery, is accomplished using special tools to aid the surgeon in accomplishing relatively complex tasks in very small incisions. Laparoscopic operation is low-risk, minimally invasive procedure that facilitates recovery periods of operations thanks to its small incisions $(0.5-1.5 \mathrm{~cm})$. It also provides less pain, small scars, quick recovery, and short hospital stays upon the surgery, hence, it has low-level risk of hospitalacquired infections, especially the surgical site infections [1-3]. Laparoscopic operations use relatively long surgical tools $(40-45 \mathrm{~cm})$, which are inserted through trocars into the abdomen. One of incisions is used for the light and the camera insertion. Surgeon operates using the visual feedback obtained from the camera. Forceps, hooks, scissors, dissectors and probes are among the most commonly used surgical instruments in the laparoscopic operations. Removal of the appendix, gallbladder, and parts of the intestines are among the various procedures that laparoscopic surgery is often performed [4-6]. 
While laparoscopic surgery presents less risk of complications for the patients, the operation is more complicated compared to open surgeries due to its limited working area. Surgeons have limited motion capability, reduced tactile sensation and depth perception; therefore their dexterity is decreased $[7,8]$.

In order to overcome these limitations and provide more ergonomic operation conditions to the surgeons, some improvements have been recently performed [9]. Multi-functional laparoscopic tools have been developed to avoid complications arise due to changing tools such as gas leakage from the abdomen, focusing the same tool-tip during the operation and readjusting camera properties [10,11]. Moreover, these tools decreased the operation time. Their designs made these instruments superior to be used in the robotic-assisted surgeries where only one robotic arm might control several tools. Hence, the necessity of using multiple robotic arms to mount the surgical instruments will disappear and more economic and surgeon-friendly robots might be developed thanks to modernization of laparoscopic instruments [12].

In this study, we present a motorized-laparoscopic-surgery tool that has been designed as a multi-functional laparoscopic instrument for appendectomy operations [10]. As mentioned above, appendectomy is an operation involving the removal of the appendix, usually after a patient is diagnosed with appendicitis, the infection of the appendix [13]. Scissor, endo-loop, endobag are three main laparoscopic instruments, which are commonly used in appendectomy. The procedure starts with inserting a $10-12-\mathrm{mm}$ diameter trocars (port, tubing) in to the incisions. One of them is allocated for the laparoscopic camera to transfer the desired part of the operation area on the screen. Using the other trocars, laparoscopic instruments are placed through the abdominal cavity to isolate appendix from the vessels and fat tissue. Next, endoloop squeezes the appendix, and then endobag covers the appendix. Scissor cuts the appendix through the endloop-knot, and the appendix is taken out in the endobag through the trocar. This process takes $30-40$ minutes. The multi-functional appendectomy device developed by Elif et al. [10] combined the scissor, endoloop and endobag in one laparoscopic instrument that is dedicated for the appendectomy. As a result, appendectomy becomes fast, easy, safe, stable and physically less tiring for the surgeon.

Here, we motorized and controlled the multi-functional laparoscopic appendectomy device. We performed MATLAB simulations for position control of the scissor, endoloop and endobag. Our results presents PID-based position control for the motorized-multi-functional laparoscopic instrument. 


\section{Methods}

Design of the multi-functional laparoscopic appendectomy device was performed using Solidworks (2015) as previously reported in [10]. Although our results will present the MATLAB/Simulink results of the scissor (main body), endoloop, and endobag, Figure 1 shows the schematic of the multi-functional laparoscopic appendectomy device based on Solidwork designs.

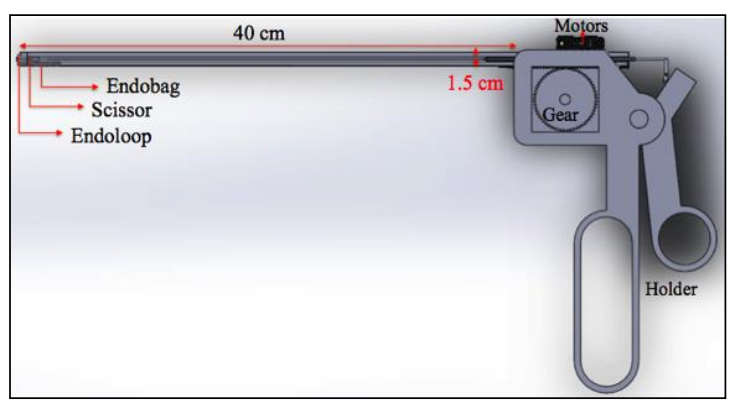

Fig. 1. Design of the motorized, multi-functional laparoscopic appendectomy device.

The SolidWorks files were transferred into MATLAB/Simulink (2017b) files to be able to control virtual motors, gears and the tips of the laparoscopic tools. Figure 2 shows the position control of the multi-functional laparoscopic appendectomy device in the MATLAB/Simulink.

To define the relation of a revolutionary gear with a prismatic link the rack and pinion constraint was defined, Figure 3 illustrates the control block diagram of the endobag in Simulink.

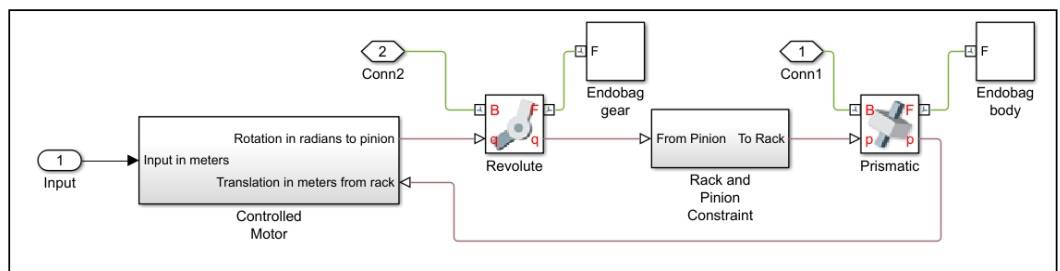

Fig. 2 Representation and control of endobag in MATLAB/Simulink (2017b). 


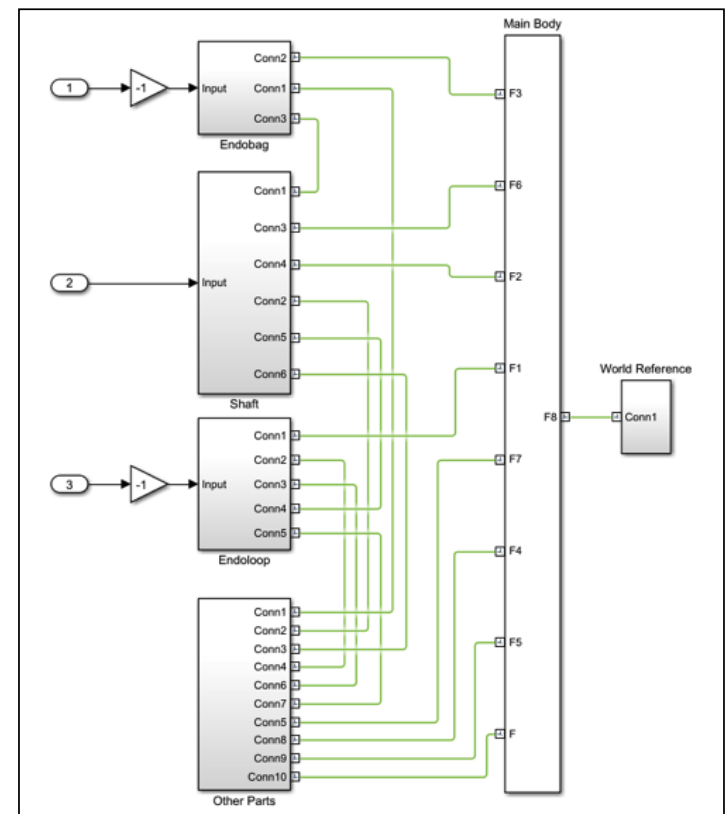

Fig. 3 Position control block diagram of the multi-functional laparoscopic appendectomy device in the MATLAB/Simulink.

The rack prismatic motion and the pinion revolute motion is tightly linked in the Simulink model [14]. A servomotor was simulated for each gear by adding a feedback loop to a simulated DC motor model, whose values were taken from the Herkulex DRS-0201 Smart Servo motor. This feedback loop uses a PID controller as illustrated in Figure 4. The control loop of each gear is identical; the only difference is the gear ratio used for the gear-link pairs. In the case of the endoloop and endobag, they are identical. The gear ratio of the scissor (main invasive body) is different in size, and its cylindrical constraints in MATLAB/Simulink (2017b) need to be changed to have no target states for the kinematics to be calculated without an error. To tune the PID controllers, MATLAB/Simulink's internal autotune function was used.

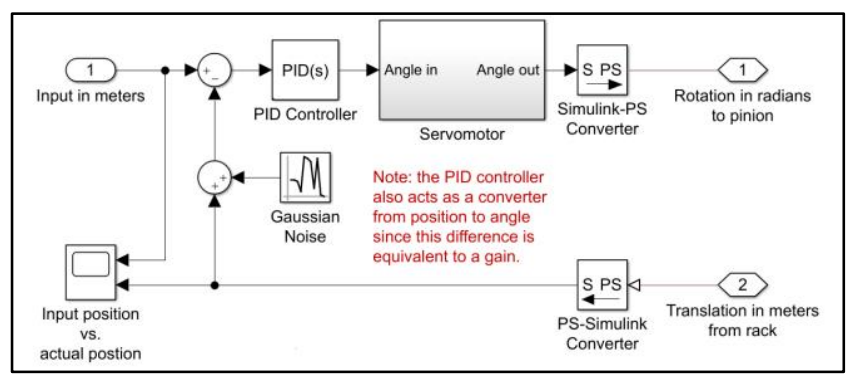

Fig. 1 Representation of the motor control architecture in Simulink. 


\section{Results}

Position control of the endoloop, endobag and scissor were tested applying a 1$\mathrm{cm}$ step response both in the absence and presence of Gaussian noise (Mean: 0, variance: $10^{-8} \mathrm{~m}$ ). Using MATLAB's PID auto-tune function, two sets of values were found.

In set $\mathrm{A}$, we attempt to minimize the overshoot and the settling and rise times, to the extent that the simulation allows as to. In set B, we find sub-optimal PID values that are uniform for all parts and are within feasible ranges.

Table 1 shows set A PID controller parameters for each part of the simulated motorized, multi-functional laparoscopic appendectomy device. Table 2 and Figures 5-6 present the step response characteristics of the endoloop, endobag and scissor. Table 3 shows the parameters of set B. Table 4, with figures 7-8, show the step response characteristics of set $\mathrm{B}$.

Table 1. Set A of PID values for part motors

\begin{tabular}{|l|l|l|l|l|}
\hline Part & $\begin{array}{l}\text { Proportional } \\
\text { (P) }\end{array}$ & $\begin{array}{l}\text { Integral } \\
\text { (I) }\end{array}$ & $\begin{array}{l}\text { Derivative } \\
\text { (D) }\end{array}$ & $\begin{array}{l}\text { Filter } \\
\text { Coefficient (N) }\end{array}$ \\
\hline Endobag & 2315 & 7625 & 173.8 & 8780 \\
\hline Endoloop & 2315 & 7625 & 173.8 & 8780 \\
\hline $\begin{array}{l}\text { Main } \\
\text { body }\end{array}$ & 663.2 & 2255 & 48.71 & 8232 \\
\hline
\end{tabular}

Table 2. Step Response Characteristics of Set A

\begin{tabular}{|l|l|l|l|l|}
\hline Part & $\begin{array}{l}\text { Overshoot } \\
\mathbf{( \% )}\end{array}$ & $\begin{array}{l}\text { Settling time } \\
(\mathbf{m s})\end{array}$ & $\begin{array}{l}\text { Steady state } \\
\text { error }(\mathbf{m m})\end{array}$ & $\begin{array}{l}\text { Rise time } \\
\mathbf{( m s )}\end{array}$ \\
\hline Endobag & 2.68 & 40.8 & 0.00 & 14.9 \\
\hline Endoloop & 2.68 & 40.8 & 0.00 & 14.9 \\
\hline Main body & 2.03 & 317 & 0.00 & 16.3 \\
\hline
\end{tabular}


Table 3. Set B of PID values for part motors

\begin{tabular}{|l|l|l|l|l|}
\hline Part & $\begin{array}{l}\text { Proportional } \\
\text { (P) }\end{array}$ & $\begin{array}{l}\text { Integral } \\
\text { (I) }\end{array}$ & $\begin{array}{l}\text { Derivative } \\
\text { (D) }\end{array}$ & $\begin{array}{l}\text { Filter } \\
\text { Coefficient (N) }\end{array}$ \\
\hline Endobag & 319.8 & 1857 & 13.64 & 1305 \\
\hline Endoloop & 319.8 & 1857 & 13.64 & 1305 \\
\hline $\begin{array}{l}\text { Main } \\
\text { body }\end{array}$ & 95.93 & 557.1 & 4.092 & 1305 \\
\hline
\end{tabular}

Table 4. Step Response Characteristics of Set B

\begin{tabular}{|l|l|l|l|l|}
\hline Part & $\begin{array}{l}\text { Overshoot } \\
\mathbf{( \% )}\end{array}$ & $\begin{array}{l}\text { Settling time } \\
(\mathbf{m s})\end{array}$ & $\begin{array}{l}\text { Steady state } \\
\text { error }(\mathbf{m m})\end{array}$ & $\begin{array}{l}\text { Rise time } \\
(\mathbf{m s})\end{array}$ \\
\hline Endobag & 3.59 & 612 & 0.00 & 142 \\
\hline Endoloop & 3.59 & 612 & 0.00 & 142 \\
\hline Main body & 3.59 & 612 & 0.00 & 142 \\
\hline
\end{tabular}
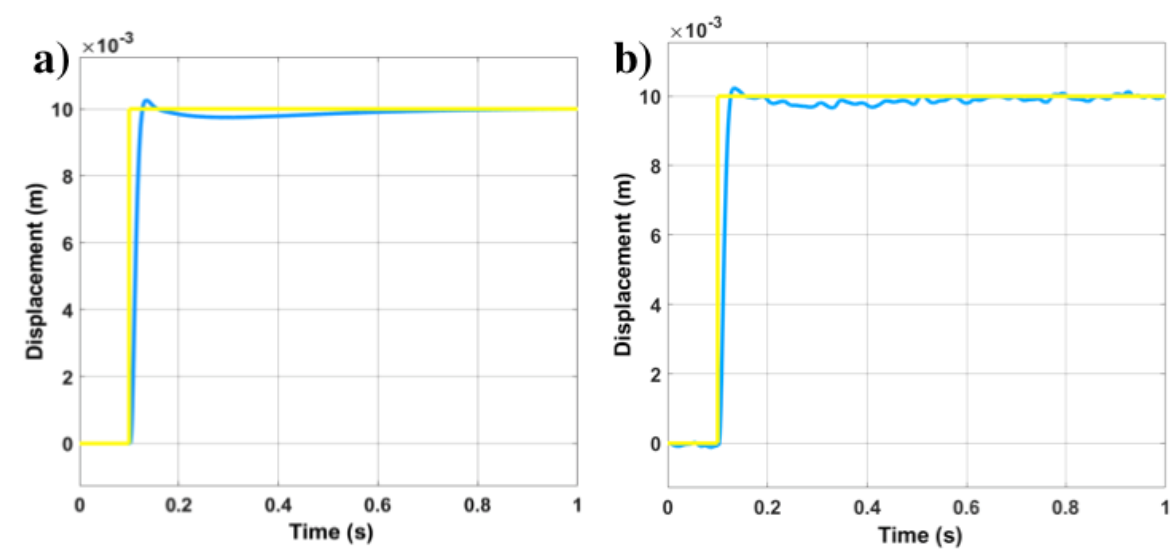

Fig. 5 For set A, position control for the endoloop and endobag. Step input is applied as reference (yellow), and positions of the tips are presented (blue). a) Without noise, b) with noise. 

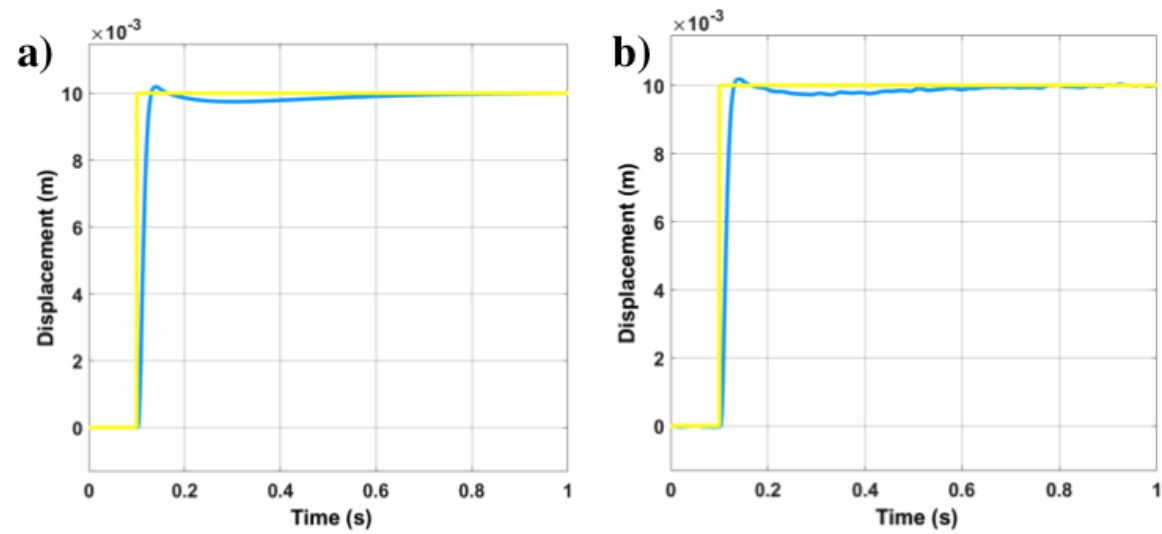

Fig. 6 For set A, position control for the scissor (main body). Step input is applied as reference (yellow), and positions of the tip is presented (blue). a) Without noise, b) with noise.
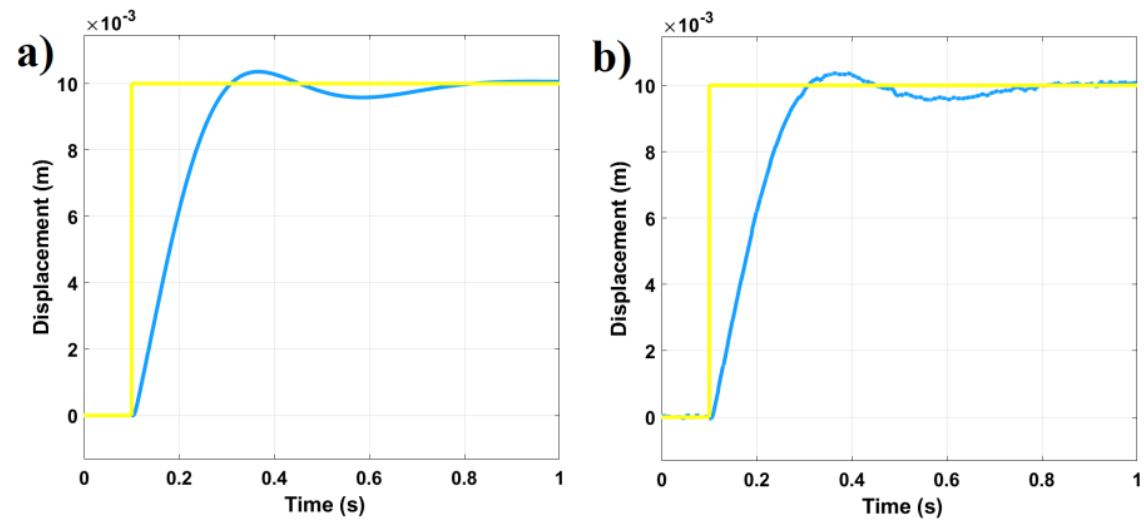

Fig. 7 For set B, position control for the endoloop and endobag. Step input is applied as reference (yellow), and positions of the tips are presented (blue). a) Without noise, b) with noise. 

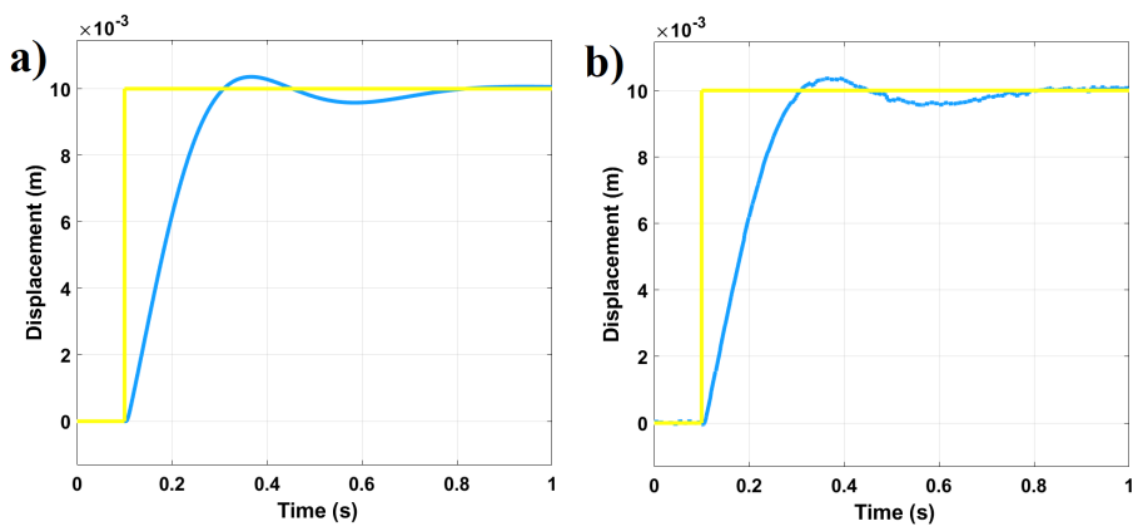

Fig. 8 For set B, position control for the scissor (main body). Step input is applied as reference (yellow), and positions of the tip is presented (blue). a) Without noise, b) with noise.

\section{Discussion}

Here we present the simulation results for the position control of the motorized laparoscopic surgery tool. Still most of the laparoscopic surgery tools are manual. Our preliminary results show that a robust, fast and accurate position control of the laparoscopic surgery tool. Previously, moving the gear manually controlled the position of the tool-tips [10]. The PID control is one of the simplest and most widely used control architectures for industrial tools in automation. It is also convenient for the control of surgical tools in medicine. Furthermore, it is economic to implement. Stability, accuracy, repeatability and reliability of the tools can be achieved applying various control architectures according to microenvironment of the operating area and the task of the operation. The results also show response performance comparable to that of surgeons, with surgeons usually having an accuracy in the $\mu \mathrm{m}$ to $\mathrm{mm}$ range [15] [16]. Today robotic systems are still very expensive to be able to part of every operating room in hospitals [12]. Therefore, development of cheaper, portable and user-friendly robotic systems or tools will be very valuable. Automated robotic-assisted surgery in conjunction with artificial intelligence will significantly contribute to the surgery and medicine in near future. 


\section{References}

[1] H.C. Clarke, "Laparoscopy—new instruments for suturing and ligation". Fertil. Steril. 23 (4): 274-7, 1972.

[2] P. Hunter, The cutting edge, A synergy of modern surgical techniques and science improves patient survival and recovery". EMBO Reports, Cilt: 8, No: 11, S: 999-1002, 2007.

[3] J.I. Alexander, M. G. Hull MG. "Abdominal pain after laparoscopy: the value of a gas drain". Br J Obstet Gynaecol. 94 (3): 267-9, 1987.

[4] R. Mirhashemi, B.L. Harlow, E.S. Ginsburg, L.B. Signorello, R. Berkowitz, S. Feldman, "Predicting risk of complications with gynecologic laparoscopic surgery". Obstet Gynecol. 92 (3): 327-31, 1998.

[5] R.M. Jimenez-Rodríguez, J.J. Segura-Sampedro, "Laparoscopic approach in gastrointestinal emergencies". World Journal of Gastroenterology. 22 (9): 2701, 2016.

[6] D. Bhandarkar, G. Mittal, R. Shah, A. Katara, T.E. Udwadia E. "Single-incision laparoscopic cholecystectomy: How I do it?". Journal of Minimal Access Surgery. 7 (1): 17-23, 2011.

[7] E.P. Westebring-van der Putten, R.H.M. Goossens, J.J, Jakimowicz, J. Dankelman, "Haptics in Minimally Invasive Surgery - A Review". Minimally Invasive Therapy. 17 (1): 3-16, 2008.

[8] A. G. Gallagher, N. McClure; J. McGuigan, K. Ritchie, N. P. Sheehy, “An Ergonomic Analysis of the Fulcrum Effect in the Acquisition of Endoscopic Skills". Endoscopy. 1 (7): 617 620, 2007.

[9] J.C. Rosser, L.E. Rosser, R.S. Savalgi, "Skill acquisition and assessment for laparoscopic surgery", Arch. Surg., Cilt: 132, S: 200-204, 1997.

[10] E. Taskin, E. Kurt, M. Elitas, and T. Tansug, "Çok fonksiyonlu apendektomi cihazı", Otomatik Kontrol Ulusal Toplantısı, 2017.

[11] M.I. Frecker, J. Schadler, R.S. Haluck, K. Culkar, and R. Dziedzic, "Laparoscopic Multifunctional Instruments: Design and Testing of Initial Prototypes”JSLS, Cilt: 9, S: 105-112, 2005.

[12] “da Vinci Surgery” Internet: http://www.davincisurgery.com/, July 10, 2017.

[13] Sallinen V., Mentula P. "Laparoscopic appendectomy", Duodecim, 133(7): 660-666, 2017.

[14] R.G. Budyans, J.K Nisbett, et al., Shigley’s mechanical engineering desing. 9. McGraw-Hill New York, 2008.

[15] L. R. Podsedkowski, J. Moll, M. Moll, and Ł. Fracczak, “Are the surgeon's movements repeatable? an analysis of the feasibility and expediency of implementing support procedures guiding the surgical tools and increasing motion accuracy during the performance of stereotypical movements by the surgeon," Kardiochirurgia i torakochirurgia polska=Polish journal of cardio-thoracic surgery, vol. 11, no. 1, p. 90, 2014.

[16] C. N. Riviere, R. S. Rader, and P. K. Khosla, "Characteristics of hand motion of eye surgeons, "in Engineering in Medicine and Biology society, 1997. Proceedings of the 19th Annual International Conference of the IEEE, vol. 4, pp. 1690-1693, IEEE, 1997. 